\title{
Explanation of Children's Health through Parents' Mental Health and Job Satisfaction by Structural Equation Modeling
}

\author{
Majid Golzarpour ${ }^{1}$, Meroe Vameghi ${ }^{1}$, Homeira Sajjadi ${ }^{1}$ \& Gholamreza Ghaedamini Harouni ${ }^{1}$ \\ ${ }^{1}$ Social Welfare Management Research Center, University of Social Welfare and Rehabilitation Sciences, Tehran, \\ Iran \\ Correspondence: Meroe Vameghi, Social Welfare Management Research Center, University of Social Welfare \\ and Rehabilitation Sciences, Koodakyar Alley, Daneshjoo Blv, Velenjak, Tehran, Iran. Tel: 98-91-2336-6200. \\ E-mail: m_vameghi@yahoo.com
}

Received: May 14, 2016 Accepted: June 6, 2016 Online Published: June 30, 2016

doi:10.5539/gjhs.v9n2p166

URL: http://dx.doi.org/10.5539/gjhs.v9n2p166

\begin{abstract}
Background: Worldwide, much evidence exists on the influence of parents' socioeconomic conditions, including employment, on children's health. However, the mechanisms for this affect are still being investigated. Few studies have been conducted in Iran to investigate this issue. This study investigated working conditions, job satisfaction, and mental health of employed people and the association between these variables and their children's health.
\end{abstract}

Materials and Methods: In this correlational work, 200 male and female staff of the official part of Educational Organization and the schools of Mashhad with children aged 5-18 years was randomly selected. The data were gathered using a demographic questionnaire, the 20-item Minnesota Job Satisfaction Questionnaire, the 28-item General Health Questionnaire, and the 28-item Child Health Questionnaire. The data were then analyzed using SPSS. The associations under study were investigated by structural equation modeling in AMOS.

Results: Approximately $17 \%$ of the variation in the parents' job satisfaction could be explained by the parents' insurance, income, and work hours; $6 \%$ of the variation in their mental health was explained by job satisfaction, and $26 \%$ of the variation in children's health was directly explained by the parents' job satisfaction and mental health. However, approximately $32.2 \%$ of the variation in children's health could be explained in the light of the direct effect of the parents' mental health and direct and indirect effects of the parents' job satisfaction. The goodness of fit index was 0.94 .

Conclusion: Parents' job satisfaction was associated with and considerably explained children's health. Although this finding may be partially related to the job satisfaction effect on mental health, the reasons for the affect of job satisfaction on children's health and the potential mechanisms of this association require further studies.

Keywords: job satisfaction, parental mental health, children's health, parents' working conditions, structural equation modeling

\section{Introduction}

Recently, socioeconomic status has been recognized as one of the most important effective factors on health and has become increasingly important (Birch \& Gafni, 2005; CCSDH, 2015; Schneider et al., 2002; WHO, 2015). Since 2005, the World Health Organization (WHO) has emphasized that investigating the social determinants of health is a research priority for healthcare (Ahmed, Tomson, Petzold, \& Kabir, 2005). Employment is an important socioeconomic factor effecting health and is highly important because of its association with many domains in life (Hadadi, Kaldi, Sajjadi, \& Salehi, 2011). In addition to employment, job characteristics also affect life and health. These characteristics may include job security, income, working hours, vacation, and insurance facilities, collectively referred to as working conditions (Jeong, 2012).

Many studies have investigated job satisfaction and working conditions, reporting job satisfaction to be a highly effective factor on productivity and quality of work (Makowiec-Dąbrowska et al., 2008; van den Berg et al., 2008). Job satisfaction is a multidimensional concept that can be considered an overall feeling towards a job or an interrelated collection of attitudes towards different aspects of a job (Adams \& Bond, 2000). Using the most 
common instruments of job satisfaction measurement, Spector summarized different dimensions of job satisfaction as follows: being appreciated, relationships, colleagues, fringe benefits, working conditions, nature of work, nature of organization, organizational policies and processes, salary, personal growth, raise opportunities, positive feedback, job security, and supervision (Lu, While, \& Barriball, 2005).

Job satisfaction may be associated with job output (Pugno \& Depedri, 2010), job intervention in family life (Grandey, Cordeiro, \& Crouter, 2005), burnout and leaving the job (Arches, 1991; Ramoo, Abdollah, \& Piaw, 2013), and job dynamics (Kristensen \& Westergård-Nielsen, 2004). In addition, some research has demonstrated that the people who are dissatisfied with their jobs are more likely to experience adverse health outcomes, such as mental health problems (Hobbi, Moghaddasi, Hatami, Abadi, \& Anisi, 2011; Kaheh \& Heivadi, 2012) and develop cardiovascular diseases, chronic headaches, and other diseases (Harandi \& Borjali, 2005). A systematic review of 485 articles indicated that job satisfaction was mostly associated with psychological problems, such as depression, self-esteem, and anxiety, and was less associated with physical illnesses (Faragher, Cass, \& Cooper, 2005).

Working conditions affect health. Additionally, some studies have demonstrated a direct, significant association between working conditions and the health status of family members, including children (Parcel \& Menaghan, 1994; Vandell \& Ramanan, 1992; Yetis-Bayraktar, Budig, \& Tomaskovic-Devey, 2013). Parents' poor socioeconomic status, including employment, may affect children's health and development, which is an important health factor over the course of the entire lifetime and potentially influences both childhood and adulthood (Ruijsbroek et al., 2011).

Out of different dimensions of parents' employment, income, working hours, and vacation have been investigated more frequently compared to other dimensions. For example, Case et al. found that parents' full-time jobs caused an increase in family income and promotion of the children's health, and lower income levels led to poorer health outcomes (Case, Lubotsky, \& Paxson, 2001). In addition, Han and Waldfogel demonstrated that children, aged 10-14 years, of mothers with rotational shift work were more likely to commit delinquent acts and have behavioral problems at school (Han \& Waldfogel, 2007). A critical review of 23 studies reported significant associations between nonstandard work schedules and adverse child developmental outcomes (Li et al., 2013). Han and Miller found that parents' non-standard shift work, such as night work and irregular working hours, could increase the risk of depression, particularly among children (Han \& Miller, 2009).

Moreover, an investigation of the data from 16 European countries between 1969 and 1994 indicated that giving more paid vacation time was associated with decreased mortality among infants and children. In particular, the most robust negative association was derived between vacation duration and post-neonatal mortality compared to prenatal mortality, infant mortality, and low birthweight (Ruhm, 2000).

Additionally, some studies have confirmed that mental health of parents, especially mothers, affects children's health. The WHO reported that in developing countries, mothers' depression is associated with more frequent admission to neonatal care units, incidence of diarrheal diseases, decreased vaccination completion for children, and poorer physical, cognitive, social, behavioral, and affective development of infants (UNFPA, 2008). A cohort study in Australia demonstrated that prepartum depression signs were predictors of a poorer health status in the early years of childhood, which is a predictor of depression in adulthood because of increasing health-related stresses in early adulthood (Raposa, Hammen, Brennan, \& Najman, 2014).

In Iran, job satisfaction and its association with health, particularly mental health, have been frequently investigated. Some of these studies found a significant association between some or all dimensions of job satisfaction and health (Bakhshayesh, 2013; Banihashemiyan et al., 2012; Habib \& Shirazi, 2003; Hobbi et al., 2011; Kaheh \& Heivadi, 2012; Rasoli \& Eslamy, 2013; Saberi et al., 2009, Sepah Mansour et al., 2012). However, very few studies have investigated the association between parents' working conditions or job satisfaction and children's health to date. One study found a positive, significant correlation between military personnel's job satisfaction and their wives' and children's mental health (Hobbi, Moghaddasi, Hatami, AzadmarzAbadi, \& Anisi, 2011). Moreover, other studies found significant associations between burnout among nursing mothers (Shoushtari, Arabgol, Aldin, \& Elahi, 2004), as well as an association between the lack of a constant presence of fathers at home because of working far from home and children's behavioral problems (Shahgholian, 2008).

In addition to the limited number of studies on this issue, reasons for the association between the parents' job characteristics and satisfaction with children's health and the role of potential moderators have not yet been studied. This study was conducted to investigate this association and the role of parents' mental health using structural equation modeling (SEM) in a cohort of employees with different job categories in an organization. 


\section{Materials and Methods}

Study design and study population

In this correlational work conducted in 2015-2016, the study population consisted of all male and female employees of the Education Organization and the schools of Mashhad who had children aged 5-18 years.

\section{Sample Size and Sampling}

Sample size was determined using a typical method for correlational studies. According to previous works, the desirable correlation coefficient was considered 0.3 , the $95 \%$ confidence interval was 96.1 , and 0.84 with beta was 0.2 . Accordingly, the sample size was determined to be 85 people (Rafiey et al., 2008). In light of including two groups, one of men and one of women, and to account for potential dropouts (Rafiey et al., 2008), the final sample size needed was 200 people. Stratified, random sampling was adopted for this study.

In this study, gender was considered the stratum of the study. First, four education districts were selected from 13 education districts across Mashhad using a simple random sampling technique. Then, one girls' school and one boys' school were randomly selected from each district and sampling was done in the education organizations and the selected schools of the four education districts under study. The inclusion criteria were: being employed by the Education Organization or schools of Mashhad and having at least one child aged 5-18 years. If the participants had a disabled or critically ill child or did not live with their child, they were excluded from the study.

\section{Methods of Gathering Data and Instruments}

To investigate demographic characteristics and working conditions of the parents, a relevant questionnaire was used. To measure job satisfaction, the 20-item Minnesota Job Satisfaction Questionnaire was administered. The parents' mental health was measured using the General Health Questionnaire (GHQ-28) and the children's health status was assessed with the 28-item Child Health Questionnaire. After the Education Organization and the parents provided the required consent to gather the data, the researchers administered the job satisfaction and child health questionnaires to the parents with at least one child aged 5-18 years. The parents with more than one child aged 5-18 years were asked to fill out the questionnaires for only one of them. The questionnaires were anonymous and the parents were told that they were free to end their participation at any time.

\section{Demographic and Working Conditions Questionnaire}

This questionnaire consisted of 18 questions to investigate demographic characteristics and working conditions consisting of work experience, working hours per week, monthly income, type of basic insurance (healthcare services, social insurance), and the presence or lack of supplemental insurance coverage.

\section{Questionnaire GHQ-28}

Goldberg and Hillier developed the 28-item GHQ-28 in 1972 (MasoudZadeh, Khalilian, Ashrafi, \& Kimia Bigi, 2004(. This questionnaire was administered to investigate the parents' general health. Each item is scored using a four-point (0-3) scale, with the total score ranging from 0 to 84 . The cut-off point is considered 9 for subscales (physical signs, anxiety, social dysfunction, and depression) and 23 for the whole questionnaire. The lower the score, the better the general health status (MasoudZadeh, Khalilian, Ashrafi, \& Bigi, 2004). This questionnaire has already been validated in the Tehran Psychiatric Institute (Harouni, Boroujeni, Jafari, \& Boroujeni, 2014). The reliability of the whole questionnaire and the subscales of physical signs, anxiety, social dysfunction, and depression was 0.91 and $0.87,0.89,0.88$, and 0.79 , respectively.

\section{Minnesota Job Satisfaction Questionnaire}

Weiss et al. developed the Minnesota Job Satisfaction Questionnaire with one short 20-item version and two long 109-item versions (Weiss, Dawis, \& England, 1967). In this work, the short version was used. This questionnaire is based on the presupposition that job satisfaction or dissatisfaction is a part of a bipolar continuum and measures job satisfaction by aggregating the scores of two subscales, intrinsic and extrinsic satisfaction (Aqda et al., 2013). The items of this questionnaire are scored using a Likert scale with minimum and maximum scores of 20 and 100, respectively. The scores 0-47 represent low job satisfaction, 48-76 moderate job satisfaction, and 77-100 high job satisfaction (Weiss, Dawis, \& England, 1967). In this study, Cronbach's alpha was 0.845, 0.837, and 0.897 for intrinsic satisfaction, extrinsic satisfaction, and the whole questionnaire, respectively.

\section{28-Item Child Health Questionnaire}

Landgraf and Abetz developed the Child Health Questionnaire. There are four versions, one self-administered 87 -item version and three 28,50 , and 98 -item versions, which are administered to parents with children aged 
5-18 years (Landgraf \& Abetz, 1996). In this study, the 28-item version was used. This questionnaire consists of 13 subscales that generally measure physical health (physical functioning or problems and limitations, general health, and bodily pain) and psychosocial health (social, affective-behavioral limitations, self-esteem, mental health, behavior, and family problems; Drotar, Schwartz, Palermo, \& Burant, 2006).

The 28-item version of this questionnaire is scored using a Likert scale with minimum and maximum scores of 28 and 133, respectively, according to the minimum and maximum scores and the number of items on each subscale. The validity of this questionnaire has already been confirmed (Gharehbaghy \& Vafaie, 2007). In a study on students in Iran, Cronbach's alpha was reported to be 0.70 and 0.85 for physical and psychosocial health, respectively (Gharehbaghy \& Vafaie, 2007). In addition, Golzarpour et al. investigated the validity of this questionnaire.

In this study, using a first-order factor analysis, 22 questions remained in the light of factor loads and goodness of fit indices (GFI $=0.885$, CFI $=0.925$, RMSEA $=0.056$ ). In the second-order factor analysis (GFI $=0.869$, $\mathrm{CFI}=0.907$, RMSEA $=0.06$ ), it was found that the items of the questionnaire could be integrated. Moreover, total internal consistency was reported to be 0.851 via a Cronbach's alpha and ICC 0.751 after modifications, which are acceptable coefficients (Golzarpour, Vameghi, Sajjadi, \& Harouni, 2016).

For modeling investigations, SEM was used in AMOS 22. The research model consisted of three latent variables, job satisfaction, general health, and child health. To assess the model, normalized chi-square $(\chi 2 / \mathrm{df})$ and root mean square error of approximation (RMSEA), goodness-of-fit index (GFI), and comparative fit Index, were used. Non-significant values of $(\chi 2 / \mathrm{df})$, RMSEA $<0.80, \mathrm{CFI}>0.90$, and GFI $>0.90$ represented acceptable GFI of the model. The significant path coefficients were investigated using critical ratio and standard error (Ghassemie, 2014).

\section{Results}

Table 1 shows the demographic characteristics of the parents and the children on whom their parents filled out the health questionnaire. It also illustrates the parents' working conditions, including mean work experience, working hours, income, and basic and supplemental insurance.

Table 1. Distribution of demographic characteristics in the participants

\begin{tabular}{lll}
\hline Demographic characteristics & Mean & Standard deviation \\
\hline Age & No. & \% \\
Parents & 41.5 & 5.9 \\
Children & 11.5 & 4.2 \\
Child's gender & No. & $\%$ \\
Female & 104 & 52 \\
Male & 96 & 48 \\
Parent's gender & No. & $\mathbf{\%}$ \\
Female & 101 & 50.5 \\
Male & 99 & 49.5 \\
Parent's educational level & No. & $\mathbf{\%}$ \\
Elementary & 6 & 3 \\
Secondary & 17 & 8.5 \\
High school & 17 & 8.5 \\
Associate degree & 18 & 9 \\
BSc/BA & 107 & 53.5 \\
MSc/MA & 32 & 16 \\
PhD & 3 & 1.5 \\
Total & 200 & 100 \\
\hline
\end{tabular}




\subsection{Parents' Working Conditions, Job Satisfaction, and Mental Health}

Table 2 shows the parents' job satisfaction and mental health.

Table 2. Parents' working conditions, job satisfaction, and mental health

\begin{tabular}{|c|c|c|c|c|c|}
\hline Scale & Subscales & Mean & $\begin{array}{l}\text { Standard } \\
\text { deviation }\end{array}$ & Maximum & Minimum \\
\hline \multirow{7}{*}{ Mental health } & Job satisfaction & 64.77 & 14.1 & 98 & 20 \\
\hline & Somatization & 8.68 & 4.42 & 20 & 0 \\
\hline & $\begin{array}{l}\text { Anxiety and } \\
\text { sleeplessness }\end{array}$ & 8.35 & 5.09 & 21 & 0 \\
\hline & Social dysfunction & 11.52 & 4.63 & 21 & 0 \\
\hline & Depression & 3.15 & 4.04 & 20 & 0 \\
\hline & Total score & 31.70 & 13.35 & 73 & 0 \\
\hline & $\begin{array}{l}\text { Work experience } \\
\text { (year) }\end{array}$ & 30 & 3 & 18.43 & 6.96 \\
\hline \multirow{4}{*}{$\begin{array}{l}\text { Work } \\
\text { conditions }\end{array}$} & $\begin{array}{l}\text { Working hours a } \\
\text { month }\end{array}$ & 48 & 18 & 38.84 & 6.42 \\
\hline & $\begin{array}{l}\text { Monthly income } \\
\text { (Rials) }\end{array}$ & $30,000,000$ & $6,000,000$ & $13,000,000$ & $4,000,000$ \\
\hline & Insurance status & \multicolumn{2}{|c|}{$\begin{array}{l}\text { Being covered by social } \\
\text { insurance }\end{array}$} & \multicolumn{2}{|c|}{$\begin{array}{l}\text { Being covered by supplemental } \\
\text { insurance }\end{array}$} \\
\hline & & \multicolumn{2}{|c|}{$143(71.5 \%)$} & \multicolumn{2}{|c|}{$102(51 \%)$} \\
\hline
\end{tabular}

Given the mean total score (64/77) and minimum and maximum scores (20 and 100, respectively) of job satisfaction, the job satisfaction of the staff of the Mashhad Education Organization was acceptable (Table 2). Furthermore, regarding the determined cut-off points, $8 \%$ of the staff had low levels of job satisfaction, $74 \%$ moderate levels, and $18 \%$ high levels.

The parents' mean total score of general health and mean scores of each subscale of general health are shown in Table 2. According to the cut-off point of the administered questionnaire, $41.5 \%$ of the parents had somatization problems, $38.5 \%$ anxiety, $59 \%$ social dysfunction, and $8.5 \%$ depression. According to the total scores, $68 \%$ of the parents had low general health levels.

\subsection{Children's Health Status}

For all subscales, the closer the mean scores to the maximum score, the better the health status. In the light of the children's mean scores of each subscale of general health and total scores of general health, and minimum and maximum scores of the administered questionnaire (Table 4), the children had a relatively acceptable health status in all subscales and on the whole.

Table 3. Descriptive indices of children's health

\begin{tabular}{lllll}
\hline Domains/total score & Mean & Standard deviation & Minimum & Maximum \\
\hline Children's mental health & 18.16 & 3.55 & 5 & 25 \\
Self-satisfaction & 12.02 & 2.23 & 3 & 15 \\
Children's activity status & 10.12 & 2.37 & 4 & 12 \\
Children's performance & 14.67 & 3.08 & 4 & 18 \\
Parents' worry & 7.15 & 2.43 & 2 & 10 \\
Parents' limitations & 5.75 & 2.98 & 2 & 10 \\
Children's general health & 11.37 & 2.04 & 5 & 15 \\
Total score on Child General Health Questionnaire & 79.25 & 11.6 & 47 & 105 \\
\hline
\end{tabular}




\subsection{Investigating Theoretical Model of Research}

Figures 1 and 2 illustrate the findings on the research model. According to the first model, including most of the studied variables, approximately $15 \%$ of the variation in the parents' job satisfaction could be explained by income, working hours, and insurance, $10 \%$ of the variation in the parents' general health could be explained by job satisfaction, and $27 \%$ of the variation in the children's health could be explained by the parents' job satisfaction and general health.

In the light of the findings, the association of the parents' job satisfaction was negative with their general health and positive with the children's health. Table 3 shows regression coefficients, the significance of each coefficient, and GFIs of the first model. The GFIs indicated that this model had a relatively acceptable goodness-of-fit.

However, the effects of some of the studied variables were not significant on the parents' job satisfaction and therefore the variable Insurance2 (being or not being covered by supplemental insurance) and the association of some variables with mental health were removed because of being non-significant. In addition that, the effective variables on job satisfaction were correlated (Figure 2).

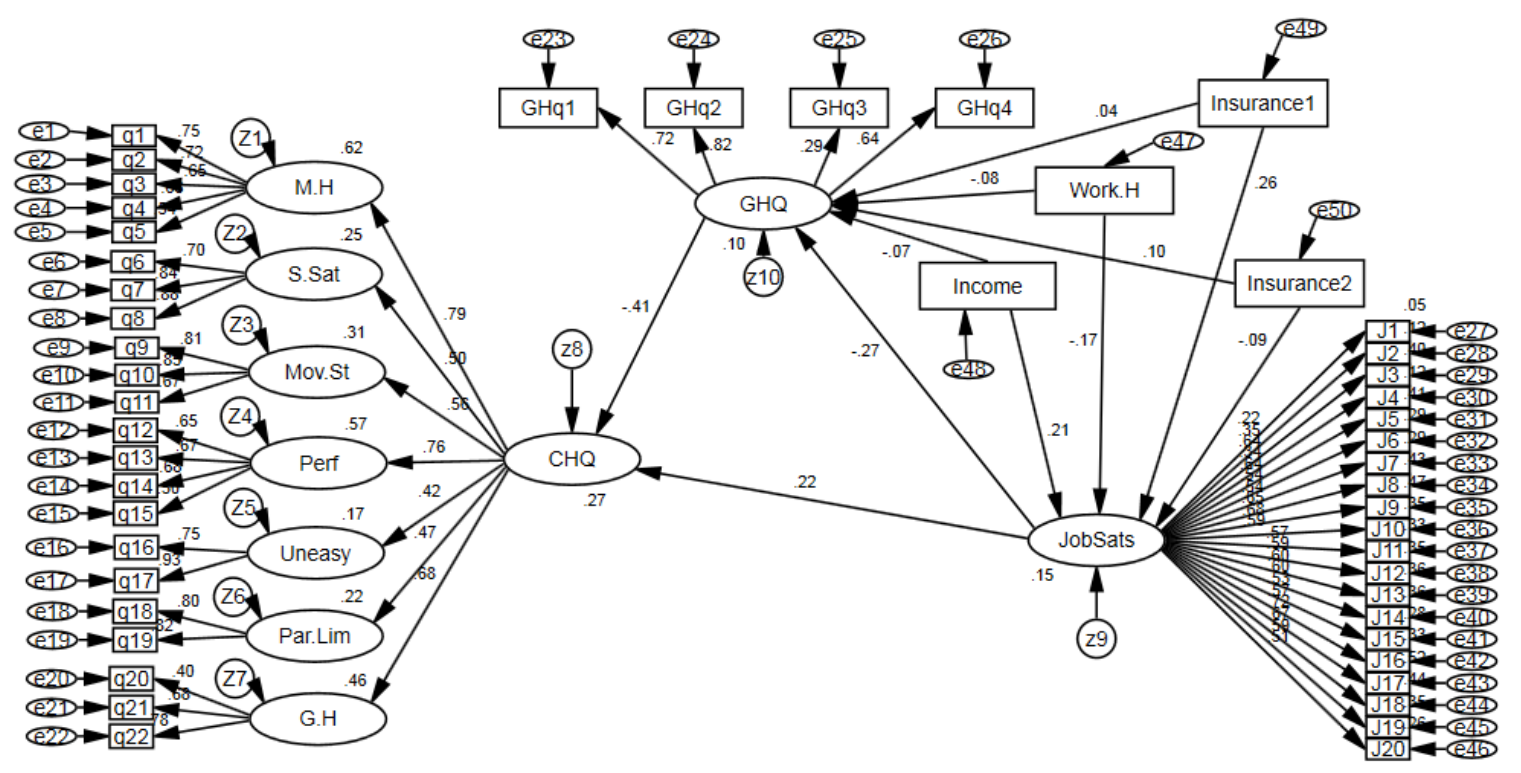

Figure 1. First research model based on primary theoretical fundamentals

Note: M.H; children's mental health, S.Sat; self-satisfaction, Mov.St; children's movement status, Perf; children's performance, Uneasy; parents' worry, Par Lim; parents' limitations, G.H; children's general health, GHQ; whole Child Health Questionnaire, GHq1; physical problems, GHq2; anxiety and sleeplessness, GHq3; social dysfunction, GHq4; depression, GHQ; general health, Insurance1; being or not being covered by social insurance, Insurance2; being or not being covered by supplemental insurance, Work.H; working hours, Income; income, JobSats; job satisfaction.

According to the second (final) research model, approximately $17 \%$ of the variation in job satisfaction could be explained by insurance status, income, and working hours, $6 \%$ of the variation in children's mental health could be explained by job satisfaction, and $26 \%$ of the variation in children's health directly could be explained by the parents' job satisfaction and mental health.

Job satisfaction both directly and indirectly affected children's health. The direct effect was 0.22 , the indirect effect was $0.103[(-0.14) \times(-0.25)]$, and the total effect of job satisfaction was $0.323[(0.14 \times 0.25)+0.22]$ on the children's health.

More clearly, given the direct effect of the children's mental health and the direct and indirect effects of the parents' job satisfaction, about $32.3 \%$ of the variation in the children's health were explained. The association of job satisfaction was negative with the children's mental health and positive with the children's health.

Regression coefficients, the significance of each coefficient, and the GFIs of the modified model are shown in Table 3. As the GFIs indicate, after elimination of the variable Insurance 2 from the first model and some of the associations, and development of correlations among effective factors on job satisfaction, first, GFIs improved 
and second, no change was seen in determining coefficients, which confirms that the second (improved) research model is economical.

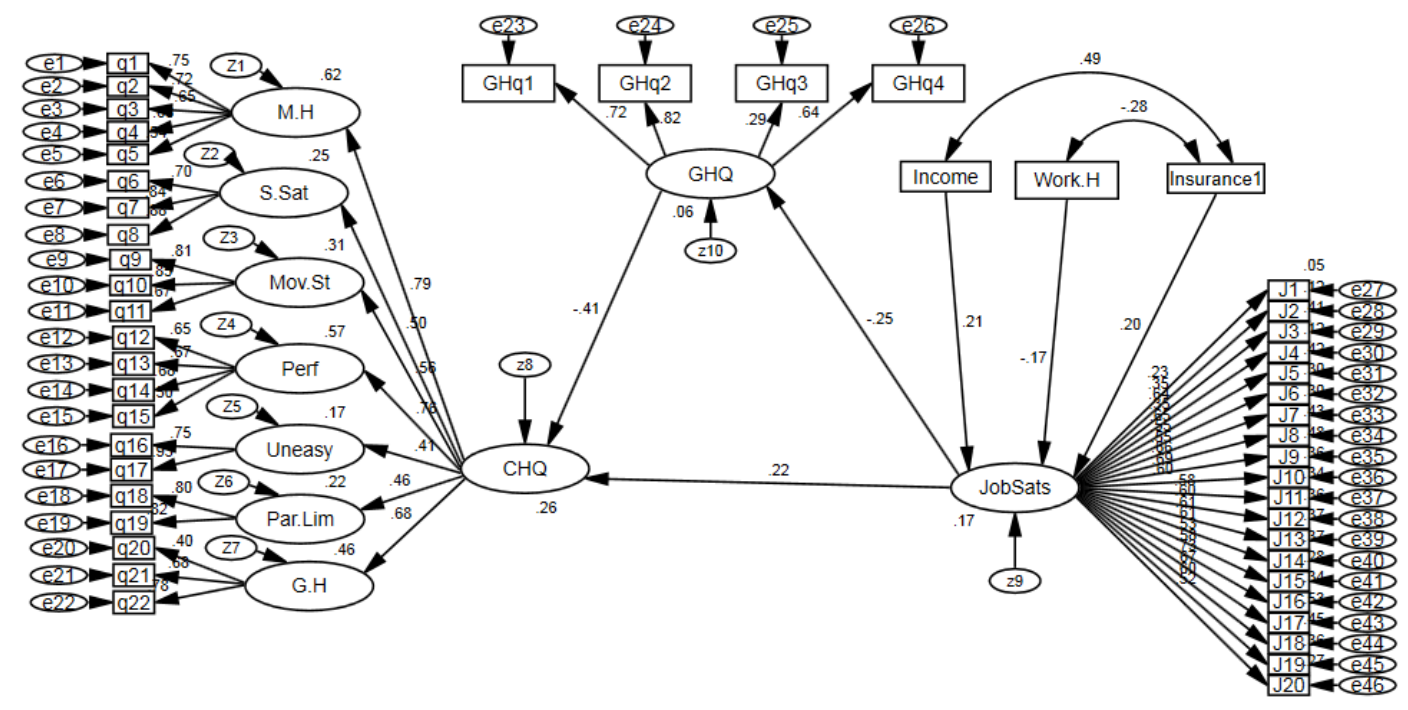

Figure 2. Primary research model after elimination of variables and insignificant associations from the first model

Table 3. Regression weights, the significance of each coefficient, and determining coefficients for the first and second research model

\begin{tabular}{|c|c|c|c|c|c|c|c|c|}
\hline Model & D.Vs. & I.Vs. & Estimate & S.E. & C.R. & B & $\mathbf{P}$ & $\mathbf{R}^{2}$ \\
\hline \multirow{11}{*}{ Model1 } & \multirow{5}{*}{ JobSats } & Income & .000 & .000 & 2.176 & .209 & 0.030 & \multirow{5}{*}{0.15} \\
\hline & & Work.H & -.008 & .004 & -1.967 & -.175 & 0.049 & \\
\hline & & Insurance2 & -.052 & .044 & -1.195 & .089 & 0.232 & \\
\hline & & Insurance1 & .167 & .070 & 2.399 & .259 & 0.016 & \\
\hline & & Work.H & -.041 & .039 & -1.055 & -.082 & 0.291 & \\
\hline & \multirow{4}{*}{ GHQ } & Income & .000 & .000 & -.867 & -.068 & 0.386 & \multirow{4}{*}{0.10} \\
\hline & & JobSats & -2.969 & 1.370 & -2.167 & -.270 & 0.030 & \\
\hline & & Insurance2 & .641 & .493 & 1.299 & .100 & 0.194 & \\
\hline & & Insurance1 & .258 & .565 & .457 & .036 & 0.648 & \\
\hline & \multirow{2}{*}{ CHQ } & GHQ & -.060 & .016 & -3.816 & -.413 & 0.000 & \multirow{2}{*}{0.27} \\
\hline & & JobSats & .345 & .177 & 1.955 & .217 & 0.05 & \\
\hline \multicolumn{9}{|c|}{ Goodness of fit indices: $\mathrm{CMIN} / \mathrm{Df}=1.87, \mathrm{GFI}=0.895, \mathrm{CFI}=0.890, \mathrm{RMSEA}=0.066$} \\
\hline \multirow{6}{*}{ Model2 } & \multirow{3}{*}{ JobSats } & Income & .000 & .000 & 2.14 & .205 & 0.045 & \multirow{3}{*}{0.17} \\
\hline & & Work.H & -.008 & .004 & -2.88 & -.168 & 0.04 & \\
\hline & & Insurance 1 & .131 & .068 & 1.94 & .203 & 0.05 & \\
\hline & GHQ & JobSats & -2.663 & 1.224 & -2.17 & -.249 & 0.030 & 0.06 \\
\hline & \multirow{2}{*}{ CHQ } & GHQ & -.060 & .016 & -3.82 & -.412 & 0.000 & \multirow{2}{*}{0.26} \\
\hline & & JobSats & .345 & .173 & 1.99 & .221 & 0.046 & \\
\hline
\end{tabular}

Goodness of fit indices: $\mathrm{CMIN} / \mathrm{Df}=1.75, \mathrm{GFI}=0.940, \mathrm{CFI}=0.901, \mathrm{RMSEA}=0.062$

Note. D.Vs $=$ Dependent variables, I.Vs $=$ Independent Variables, $\mathrm{C} . \mathrm{R}=$ Critical ratio.

\section{Discussion}

Health experts have recently investigated working conditions and their associations with staff health. In addition, parents' working conditions are associated with not only their own but also their family members' health (Parcel \& Menaghan, 1994; Vandell \& Ramanan, 1992; Yetis-Bayraktar et al., 2013). In a review of the relevant research 
conducted in Iran, we found no study specifically investigating the association between working conditions and parents' job satisfaction, and children's health, nor does anything study on how these variables are associated with each other.

In this study, to investigate the association among working conditions, the parents' job satisfaction, and children's health, the parents' mental health was also analyzed in the model as a mediating variable. Based on the final research model, the variables of working conditions, including income, being covered by supplemental insurance and working hours, were not significantly associated with job satisfaction, and $17 \%$ of the variation in job satisfaction was explained by these three variables of working conditions.

According to the findings from the first research model, none of the variables of working conditions and the parents' mental health were associated, while in both research models, job satisfaction was significantly associated with the parents' mental health, and according to the second research model, job satisfaction explained about $6 \%$ of the variation in the parents' mental health.

Faragher et al.'s study demonstrated that job satisfaction was strongly associated with mental problems and mostly correlated with depression, followed by self-esteem and anxiety (Faragher, Cass, \& Cooper, 2005). In addition, the studies conducted in Iran found that the association between job satisfaction and health, especially mental health (Banihashemiyan et al., 2012; Habib \& Shirazi, 2003; Hobbi et al., 2011; Kaheh \& Heivadi, 2012; Rasoli \& Eslamy, 2013; Saberi et al., 2009; Mansour et al., 2012), was significant in some or all of the dimensions of job satisfaction and health. The parents' job satisfaction was directly and significantly associated with the children's health in the final model and directly explained approximately $4 \%$ of the variation in the children's health. Moreover, job satisfaction explained approximately $16 \%$ of the variation in the children's health indirectly through the parents' mental health. Additionally, the direct effect of job satisfaction on the children's health in addition to its indirect effect on the children's health through the parents' mental health explained $26 \%$ of the variation in the children's health. According to the final research model, about $17 \%$ of the variation in job satisfaction could be explained by insurance status, income, and working hours, $6 \%$ of the variation in the parents' mental health by job satisfaction, and $26 \%$ of the variation in the children's health directly by job satisfaction and the parents' mental health. According to the final model, job satisfaction affected children's health not only directly but also indirectly, and given the direct effect of the parents' mental health and direct and indirect effects of the parents' job satisfaction, approximately $32.2 \%$ of the variation in the children's health was explained. These findings indicate that parents' job satisfaction can affect their children's health, and job satisfaction affects children's health both indirectly, through variations in parents' health, and directly. In addition, job satisfaction, per se, may affect some of the working conditions of parents.

Previous evidence indicates that job satisfaction is associated with employees' health, particularly mental health (Habib \& Shirazi, 2003; Kaheh \& Heivadi, 2012) on the one hand, and parents' mental health is definitely associated with children's health on the other hand (Hobbi et al., 2011; Kaheh \& Heivadi, 2012).

Furthermore, some recent investigations have demonstrated an association between psychological effects of employment and children's health. Obviously, mental and physical health is considered an asset for parents to communicate with and care for their children, because it affects both the children's development and the family processes (Barnett et al., 2008; Davis et al., 2008; Han, 2008). Fatigue due to insufficient sleep and stress due to inappropriate working conditions can influence parenting and the time spent with children to do important activities.

The stress due to non-standard work schedules can adversely affect family dynamics and family and child cohesion (Barnett et al., 2008; Davis et al., 2008; Han, 2008). Studies have demonstrated that parents' stress at work affects the quality of family interactions, thus affecting children's and adolescents' adaptation (Crouter \& Bumpus, 2001). In addition, mothers' stress at work may affect child development through decreasing maternal care (Felfe \& Hsin, 2012).

Despite the significance of parents' working conditions and the effects on children's health as an important social determinant of health in international databases, this issue has not yet been investigated adequately in Iran. Given the findings of this study, future studies are recommended to investigate this association as well as the mechanisms by which working conditions influence different socioeconomic classes.

One important limitation of the study is the sole dependency on the parents' report about their children's health status. Thus, future studies could assess children's health through children's self-report. Moreover because of insufficient sample size, assessment of the association between variables in different occupational groups was not possible. Additionally, it is presumed that more variations in parental education status may show different results. 


\section{Conclusion}

Overall, regarding the findings of this study, we can argue that parents' job satisfaction is associated with and can largely explain children's health. Although this can be partially related to job satisfaction's effect on mental health, the potential mechanisms explaining the direct affect on children's health directly require further investigations.

\section{Acknowledgments}

This paper was one part of MSc thesis. Financial support was provided by the Social Welfare Management Research Center, University of Social Welfare and Rehabilitation Sciences.

\section{Competing Interests Statement}

The authors declare that there is no conflict of interests regarding the publication of this paper.

\section{References}

Adams, A., \& Bond, S. (2000). Hospital nurses' job satisfaction, individual and organizational characteristics. Journal of Advanced Nursing, 32, 536-543. http://dx.doi.org/10.1046/j.1365-2648.2000.01513.x

Ahmed, S. M., Tomson, G., Petzold, M., \& Kabir, Z. N. (2005). Socioeconomic status overrides age and gender in determining health-seeking behavior in rural Bangladesh. Bulletin of the World Health Organization, 83, 109-117.

Aqda, M. A., Pude, Z. Y., Zarch, M. K., Rastegar, K., Dehgan, Z., \& Hakimian, E. (2013). Relationship between job satisfaction and marital satisfaction in welfare organization of Yazd City. Journal of Tolooe-Behdasht, 12, 119-132.

Arches, J. (1991). Social structure, burnout, and job satisfaction. Social Work, 36, 202-206.

Bakhshayesh, A. R. (2013). The relationship between personality types and general health with job satisfaction of Yazd Health Center staffs. Journal of Payavard-Salamat, 7, 42-55.

BaniHashemiyan, K., Jahrumi, F. G., Pirkashani, N. G., \& Sharafy, M. (2012). Relationship between general health and manager's leadership style and its effect on staff's job satisfaction in Shiraz University of Medical Sciences. Journal of Payavard-Salamat, 5, 32-40.

Barnett, R. C., Gareis, K. C., \& Brennan, R. T. (2008). Wives' shift work schedules and husbands' and wives' well-being in dual-earner couples with children: A within-couple analysis. Journal of Family Issues, 29, 396-422. http://dx.doi.org/10.1177/0192513X07305346

Birch, S., \& Gafni, A. (2005). Achievements and challenges of Medicare in Canada: Are we there yet? Are we on course? International Journal of Health Services, 35, 443-463. http://dx.doi.org/10.2190/RWA1C3PB-0KY4-HBUT

Canadian Council on Social Determinants of Health. (2015). A review of frameworks on the determinants of health. Retrieved from http://ccsdh.ca/images/uploads/Frameworks_Report_English.pdf

Case, A., Lubotsky, D., \& Paxson, C. (2001). Economic status and health in childhood: The origins of the gradient. National Bureau of Economic Research. http://dx.doi.org/10.2139/ssrn.275152

Crouter, A. C., \& Bumpus, M. F. (2001). Linking parents' work stress to children's and adolescents' psychological adjustment. Current Directions in Psychological Science, 10, 156-159. http://dx.doi.org/10.1111/1467-8721. 00138

Davis, K. D., Goodman, W. B., Pirretti, A. E., \& Almeida, D. M. (2008). Nonstandard work schedules, perceived family well-being, and daily stressors. Journal of Marriage and Family, 70, 991-1003. http://dx.doi.org/10. $1111 / \mathrm{j} .1741-3737.2008 .00541 . \mathrm{x}$

Drotar, D., Schwartz, L., Palermo, T. M., \& Burant, C. (2006). Factor structure of the Child Health Questionnaire-parent form in pediatric populations. Journal of Pediatric Psychology, 31, 127-138. http://dx.doi.org/10.1093/jpepsy/jsi078

Faragher, E. B., Cass, M., \& Cooper, C. L. (2005). The relationship between job satisfaction and health: A meta-analysis. Occupational and Environmental Medicine, 62, 105-112. http://dx.doi.org/10.1136/ oem.2002.006734

Felfe, C., \& Hsin, A. (2012). Maternal work conditions and child development. Economics of Education Review, 31, 1037-1057. http://dx.doi.org/10.1016/j.econedurev.2012.06.008

Gharehbaghy, F., \& Vafaie, M. (2007). Family emotional security and children's psychopathological symptoms 
and health: An investigation of the meditational and moderational role of children's temperament. Journal of Research in Psychological Health, 1, 5-17.

Ghassemie, V. (2014). Structural Equation Modeling in Social Researches using Amos Graphics. Tehran, Jammee Shenasan (Book).

Golzarpour, M., Vameghi, M., Sajjadi, H., \& Harouni, G. R. G. A. (n.d.). Validity and reliability of Persian Version of Children's Health-related Quality of Life. North Khorasan University of Medical Sciences Journal.

Grandey, A., Cordeiro, B., \& Crouter, A. (2005). A longitudinal and multi-source test of the work-family conflict and job satisfaction relationship. Journal of Occupational and Organizational Psychology, 78, 305-323. http://dx.doi.org/10.1348/096317905X26769

Habib, S., \& Shirazi, M. A. (2003). Job satisfaction and mental health among the employees of a general hospital. Journal of Psychiatry and Clinical Psychology, 8, 64-73.

Hadadi, M., Kaldi, A., Sajjadi, H., \& Salehi, M. (2011). Relationship between job classification and mental health in employed women. Social Welfare Quarterly, 11, 107-127.

Han, W.-J. (2008). Shift work and child behavioral outcomes. Work, Employment \& Society, 22, 67-87. http://dx.doi.org/10.1177/0950017007087417

Han, W.-J., \& Miller, D. P. (2009). Parental work schedules and adolescent depression. Health Sociology Review, 18, 36-49. http://dx.doi.org/10.5172/hesr.18.1.36

Han, W.-J., \& Waldfogel, J. (2007). Parental work schedules, family process, and early adolescents' risky behavior. Children and Youth Services Review, 29, 1249-1266. http://dx.doi.org/10.1016/j.childyouth.2007.05.011

HarandI, M. R. A., \& Borjali, A. (2005). Relationship between coping skills and job satisfaction. Journal of Psychology, 9, 186-198.

Harouni, G. R. G. A., Boroujeni, M. B., Jafari, S. E. M., \& Boroujeni, K. S. (n.d.). Effectiveness of four preventive methods on attitudes toward drug abuse and mental health among high school boys. Journal of Cognitive Science.

Hobbi, M. B., Moghaddasi, H., Hatami, H. R., AzadmarzAbadi, E., \& Anisi, J. (2011). Relationship between job satisfactions of employees with family mental health in a military unit. Journal of Military Psychology (JMP), 2, 57-66.

Jeong, I. S. (2012). Working conditions, job perceptions, job satisfaction, and intentions to stay at the job for clinical research coordinators in the Republic of Korea. Drug Information Journal, 46, 303-312. http://dx.doi.org/10.1177/0092861512436841

Kaheh, D., \& Heivadi, T. (2012). Job satisfaction \& mental health. Journal of Payesh, 11, 391-397.

Kristensen, N., \& Westergård-Nielsen, N. (2004). Does low job satisfaction lead to job mobility?

Landgraf, J. M., \& Abetz, L. N. (1996). Measuring health outcomes in pediatric populations: Issues in psychometrics and application. Quality of Life and Pharmaco Economics in Clinical Trials (2nd ed., pp. 793-802). Philadelphia: Lippincott-Raven.

Li, J., Johnson, S. E., Han, W., Andrews, S., Kendall, G., Strazdins, L., \& Dockery, A. (2013). Parents' Nonstandard Work Schedules and Child Wellbeing. A Critical Review of the Literature. http://www.wzb.eu/sites/default/files/publikationen/postprints/li_parents_nonstandard_work_schedules_and _child_wellbeing.pdf

Lu, H., While, A. E., \& Barriball, K. L. (2005). Job satisfaction among nurses: A literature review. International Journal of Nursing Studies, 42, 211-227. http://dx.doi.org/10.1016/j.ijnurstu.2004.09.003

Makowiec-Dąbrowska, T., Koszada-Włodarczyk, W., Bortkiewicz, A., Gadzicka, E., Siedlecka, J., Jóźwiak, Z., \& Janusz, P. (2008). Zawodowe I pozazawodowe determinanty zdolności do pracy. Medycyna Pracy, 59, 9-24.

Mansour, M. S., Ahmadi, M. S. Y., \& Shohami, N. (2012). Relationship between life quality, job satisfaction, and teachers' professional exhaustion. Journal of Educational Administration Research, 3, 91-110.

MasoudZadeh, A., Khalilian, A. R., Ashrafi, M., \& Kimiabigi, K. (2004). The midtrimester means arterial pressure in the prediction of pre-eclampsia. Journal of Mazandaran University of Medical Sciences, 14, 74-83.

Parcel, T. L., \& Menaghan, E. G. (1994). Parents' jobs and children's lives. Transaction Publisher, Chicago.

Pugno, M., \& Depedri, S. (2010). Job performance and job satisfaction: An integrated survey. Economia Politica, 
$27,175-210$.

Rafiey, H., Sajadi, H., Narenjiha, H., Nouri, R., Farhadi, M. H., Norouzi, S., \& Shirin Bayan, P. (2008). The interdisciplinary research methods in addiction and other problems and deviation(injuries) and social (qualitative and quantitative). Danjeh, Tehran (Book).

Ramoo, V., Abdullah, K. L., \& Piaw, C. Y. (2013). The relationship between job satisfaction and intention to leave current employment among registered nurses in a teaching hospital. Journal of Clinical Nursing, 22(21-22), 3141-52. http://dx.doi.org/10.1111/jocn.12260

Raposa, E., Hammen, C., Brennan, P., \& Najman, J. (2014). The long-term effects of maternal depression: Early childhood physical health as a pathway to offspring depression. Journal of Adolescent Health, 54, 88-93. http://dx.doi.org/10.1016/j.jadohealth.2013.07.038

Rasoli, Z., \& Eslamy, R. (2013). Survey of relationship between job satisfaction and personality type with mental health in army ground personnel. Journal of Military and Health Sciences Research, 11, 96-101.

Ruhm, C. J. (2000). Parental leave and child health. Journal of Health Economics, 19, 931-960. http://dx.doi.org/10.1016/S0167-6296(00)00047-3

Ruijsbroek, A., Wijga, A. H., Kerkhof, M., Koppelman, G. H., Smit, H. A., \& Droomers, M. (2011). The development of socio-economic health differences in childhood: Results of the Dutch longitudinal PIAMA birth cohort. BMC Public Health, 11, 1. http://dx.doi.org/10.1186/1471-2458-11-225

Saberi, H., Sharifi, H. P., Afrouz, G. A., \& Hoseinian, S. (2009). The relationship between job satisfaction, marital satisfaction and a sense of self and mental health the teachers in ordinary schools, gifted and slow step. Journal of Andisheh va Raftar (Applied Psychology), 3(12), 30-44.

Schneider, M., Castillo-Salgado, C., Loyola-Elizondo, E., Bacallao, J., Mujica, O., Vidaurre, M., \& Alleyne, G. (2002). Trends in infant mortality inequalities in the Americas: 1955-1995. Journal of Epidemiology and Community Health, 56, 538-541. http://dx.doi.org/10.1136/jech.56.7.538

Shahgholian, M. (2008). The effect of absence of father (because of working) in behavioral disorders of school students. Journal of Research in Psychological Health, 2, 29-35.

Shoushtari, M. H., Arabgol, F., Aldin, N. K., \& Elahi, F. (2004). The relationship between burnout syndrome in mothers in nursing career and their children's behavioral problems. Journal of Advances in Cognitive Science, $6,67-72$.

Unfpa, W. (2008). Maternal mental health and child health and development in low and middle income countries. Geneva, Switzerland: Report of UNFPA and WHO.

Van den berg, T. I., Alavinia, S. M., Bredt, F. J., Lindeboom, D., Elders, L. A., \& Burdorf, A. (2008). The influence of psychosocial factors at work and life style on health and work ability among professional workers. International Archives of Occupational and Environmental Health, 81, 1029-1036. http://dx.doi.org/10.1007/s00420-007-0296-7

Vandell, D. L., \& Ramanan, J. (1992). Effects of early and recent maternal employment on children from low-income families. Child Development, 63, 938-949. http://dx.doi.org/10.2307/1131245

Weiss, D. J., Dawis, R. V., \& England, G. W. (1967). Manual for the Minnesota Satisfaction Questionnaire. Minnesota Studies in Vocational Rehabilitation. University of Minnesota, Minneapolis.

World Health Organization. (2015). Health in the post-2015 health development agenda: Need for a social determinants of health approach, Joint statement of UN platform on Social Determinants of Health. Retrieved from http://www.who.int/social_determinants/advocacy/health-post-2015_sdh/en/

Yetis-Bayraktar, A., Budig, M. J., \& Tomaskovic-Devey, D. (2013). From the shop floor to the kitchen floor: Maternal occupational complexity and children's reading and math skills. Work and Occupations, 40, 37-64. http://dx.doi.org/10.1177/0730888412465879

\section{Copyrights}

Copyright for this article is retained by the author(s), with first publication rights granted to the journal.

This is an open-access article distributed under the terms and conditions of the Creative Commons Attribution license (http://creativecommons.org/licenses/by/3.0/). 